\title{
Tungsten speciation in hydrothermal ore-forming fluids
}

YUAN MEI ${ }^{1}$, WeIHUA LiU ${ }^{1}$, QIUSHI GUAN ${ }^{1,2}$, BARBARA ETSCHMANN ${ }^{2}$, JOEL BRUGGER ${ }^{2}$, XIN-SONG WANG ${ }^{3,4}$, A.E. WiLliams-JONES ${ }^{4}$

${ }^{1}$ CSIRO Mineral Resources, Kensington, WA 6151, Australia; yuan.mei@csiro.au ${ }^{2}$ Monash University, Clayton, VIC 3800, Australia ${ }^{3}$ Guiyang Institute of Geochemistry, Guiyang, 55005, China ${ }^{4}$ McGill University, Montreal H3A 0E8, Canada

Tungsten is a strategic metal mined mainly from hydrothermal tungstate minerals in which the tungsten is in both tetravalent (e.g., tungstenite, $\mathrm{WS}_{2(\mathrm{~s})}$ ) and hexavalent (e.g., scheelite, $\mathrm{CaWO}_{4(\mathrm{~s})}$, and ferberite, $\mathrm{FeWO}_{4(\mathrm{~s})}$ ) oxidation states. To understand the transport of tungsten in ore-forming fluids and develop geochemical models for the formation of these deposits, we need reliable information on the speciation and thermodynamic properties of tungsten complexes in aqueous fluids over wide ranges of temperature, pressure and chemical composition. However, there has been no direct molecular-level study of the mechanism of tungsten complexation under hydrothermal conditions, and thus the role of chlorine, sulfur and fluorine in aqueous tungsten species are poorly understood.

In this study, we combined ab initio molecular dynamic (MD) simulations and synchrotron-based in-situ X-ray absorption spectroscopy to investigate the speciation and geometry of tungsten W(VI) in sodium-, chlorine-, sulfur- and fluorine-bearing brines up to $600^{\circ} \mathrm{C}, 2 \mathrm{kbar}$. Our study shows that tungsten associates strongly with fluoride and sulfur (as thiotungstate) in hydrothermal fluids, but weakly with sodium and chloride. The thermodynamic properties of tungsten speciation derived in this study enable better understanding and quantitative modelling of tungsten mobility in hydrothermal systems. 